\title{
Design of the Control System for Plate Cutting Machine
}

\author{
Wang $\mathrm{Yao}^{1}$, Lun Fengyan ${ }^{1,{ }^{*}}, \mathrm{Xu} \mathrm{Miao}^{2}, \mathrm{Bai} \mathrm{Yan}^{3}$ \\ ${ }^{1}$ School of Mechanical Engineering, Beihua University, Jilin, China \\ ${ }^{2}$ School of automotive and architectural engineering, Beihua University, Jilin, China \\ ${ }^{3}$ Engineering Training Center, Beihua University, Jilin, China \\ *Corresponding author
}

Keywords: plate cutting machine; control system; PLC; programming

\begin{abstract}
. in this paper, the traditional plate cutting machine working principle and control requirements was analyzed. And the control system was designed. Through the analysis of the design of PLC type, input and output points distribution, external wiring, ladder diagram programming process, the plate cutting machine was provided with the high efficiency, high reliability, high degree of automation requirements.
\end{abstract}

\section{Introduction}

With the progress and development of automation technology, the degree of automation of plate cutting machine is gradually improved[1-3]. Microprocessor based programmable logic controller (PLC) can meet the requirements of high efficiency, high reliability and difficult automation in modern production. In this paper, through the analysis of the working principle and control requirements of the plate cutting machine, the detailed analysis of the selection of PLC, the allocation of input and output points, design of the external wiring, and the flow chart of the ladder diagram program are made. The main function of the cutting system is to complete the cutting and moving of the plate[4][5]. That is, through the tractor (CART), the plate is sent to the designated position (cutting gun or cutter position), and then through the cutting gun and cutter plate, cutting the plate. When a complete cutting process is finished, the cart moves forward a distance from the drive mechanism, which is the length required for the program to be set. Then continue the cutting process and cycle until the stop condition is reached.

\section{Analysis and Research on Control System of Plate Cutting Machine}

Machining Process Analysis of Cutting Machine. The process is as follows, which is shown as Fig.1.

(1) Firstly the cart carries the workpiece forward, so that the workpiece reaches the position under which the cutting gun is located, and can be detected by the limit switch at the lower part of the cutting gun.

(2) When the cart is in place, the pressing device is started and the compression is finished after the time delay.

(3) When the delay technique is over, the cutting gun falls in place.

(4) After falling in place, turn on the acetylene valve, cutting gun valve, high pressure oxygen valve in turn, and ignite the flame.

(5) After preheating for a period of time, start the cutting gun, move the motor around and start the cutting process.

(6) After cutting, the cutting gun is reset.

(7) Loosen the pressing mechanism, and move the fixed length under the driving of the stepping motor.

(8) The cutting gun is used again, and the cutting cycle is carried out. 


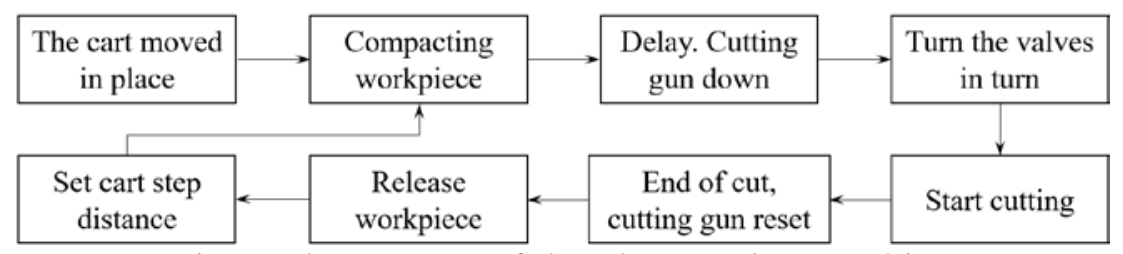

Fig. 1 The process of the plate cutting machine

Detection of Input Signals. The cutting machine control system mainly completes the operation button input detection, cart transportation in place detection, cutting gun position detection, cart step in place detection.

Detection of Output Signals. Control output are: the stepper motor control, motor control of the cutting gun around, cutting gun solenoid valve control valve, gas cutting gun control, pressing device control.

\section{I/O Allocation}

In this control system, the required inputs are basically digital, mainly including a variety of control buttons and various limit switches, a total of 19 digital inputs, as is shown in Table 1.

Table 1 Input address and input device

\begin{tabular}{|c|c|c|c|}
\hline $\begin{array}{c}\text { Input } \\
\text { address }\end{array}$ & Input device & $\begin{array}{c}\text { Input } \\
\text { address }\end{array}$ & Input device \\
\hline $\mathrm{I} 0.0$ & Emergency stop & $\mathrm{I} 1.2$ & Manual cart forward \\
\hline $\mathrm{I} 0.1$ & Reset & $\mathrm{I} 1.3$ & Manual cart astern \\
\hline $\mathrm{I} 0.2$ & Manual / Automatic & $\mathrm{I} 1.4$ & Manual workpiece compression \\
\hline $\mathrm{I} 0.3$ & Automatic cutting start & $\mathrm{I} 1.5$ & Manual workpiece release \\
\hline $\mathrm{I} 0.4$ & Manual cutting gun rises & $\mathrm{I} 1.6$ & Cutting gun upper limit switch \\
\hline $\mathrm{I} 0.5$ & Manual cutting gun down & $\mathrm{I} 1.7$ & Lower limit switch of cutting gun \\
\hline $\mathrm{I} 0.6$ & Manual cutting gun shift left & $\mathrm{I} 2.0$ & Cutting gun left limit switch \\
\hline $\mathrm{I} 0.7$ & Manual cutting gun shift right & $\mathrm{I} 2.1$ & Right limit switch for cutting gun \\
\hline $\mathrm{I} 1.0$ & Manual cutting gun acetylene valve & $\mathrm{I} 2.2$ & Cart switch \\
\hline $\mathrm{I} 1.1$ & Manual cutting gun oxygen valve & & \\
\hline
\end{tabular}

In this control system, the main output control equipment has all kinds of contactors and motors, and there are 10 output points, and the specific allocation is shown in Table 2.

Table 2 Output address and output device

\begin{tabular}{|c|c|c|c|}
\hline $\begin{array}{c}\text { Output } \\
\text { address }\end{array}$ & output device & $\begin{array}{c}\text { Output } \\
\text { address }\end{array}$ & output device \\
\hline Q0.0 & Step motor pulse output & Q0.5 & Cutting gun down solenoid valve \\
\hline Q0.1 & Stepping motor direction & Q0.6 & Acetylene valve for cutting gun \\
\hline Q0.2 & Cutting gun motor forward contactor & Q0.7 & Cutting gun cutting oxygen valve \\
\hline Q0.3 & Cutting gun motor reverse contactor & Q1.0 & Cutting gun high pressure oxygen valve \\
\hline Q0.4 & Cutting gun rising solenoid valve & Q1.1 & pressing device \\
\hline
\end{tabular}

\section{Control System External Wiring}

The SIEMENS S7-200 series PLC is used as the host of the panel cutting control system. The wiring diagram has 19 inputs and 10 outputs, as shown in Fig.2. 


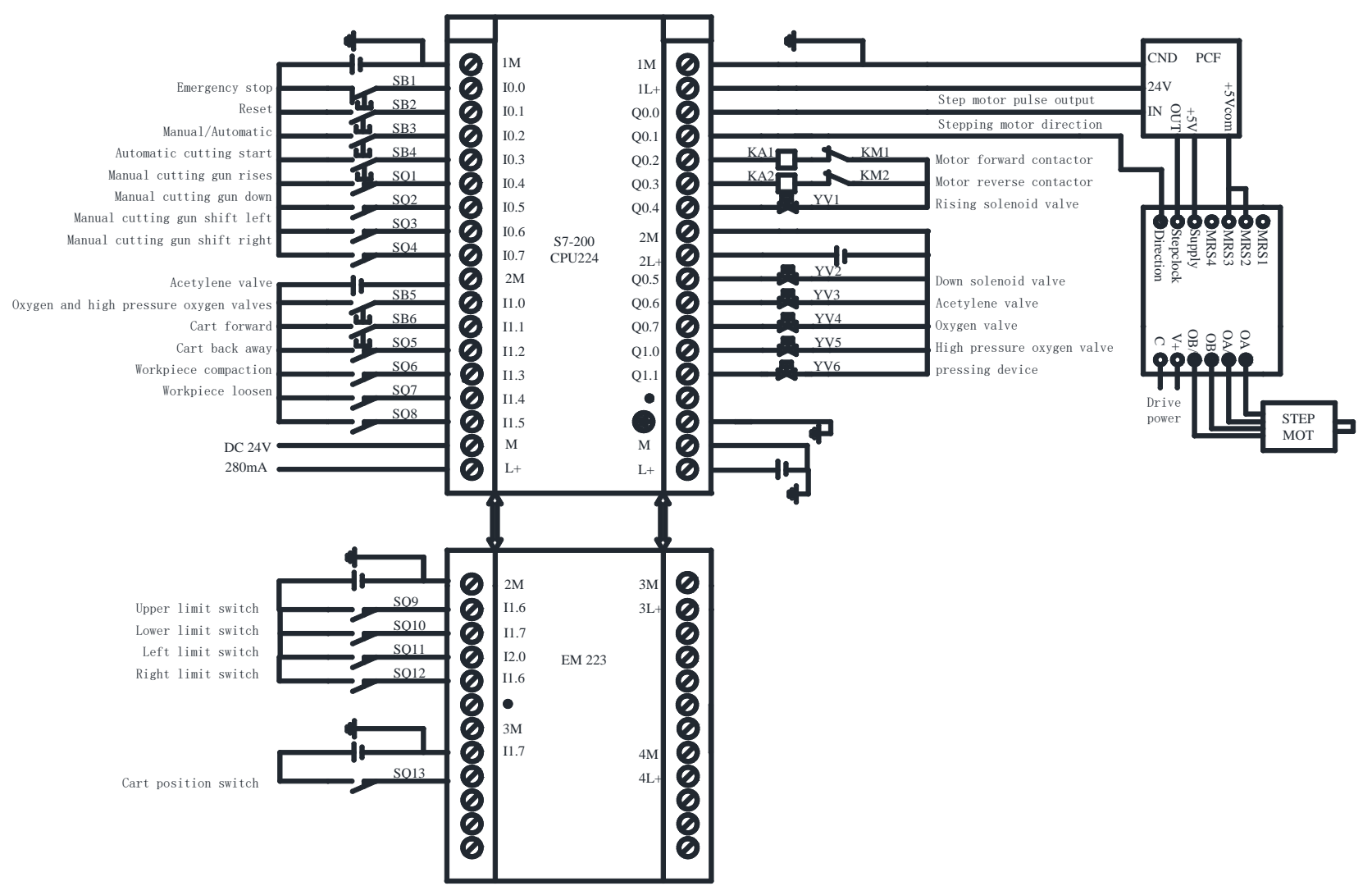

Fig. 2 Control system external wiring

\section{Software Design}

According to the functional requirement of the control system, the control process of plate cutting is divided into manual control mode and automatic control mode, the manual control mode, each device can be run separately, no order of each other, do not interfere with each other.

In manual control mode, the operation of each device can be controlled separately. The manual mode flow diagram is as follows:

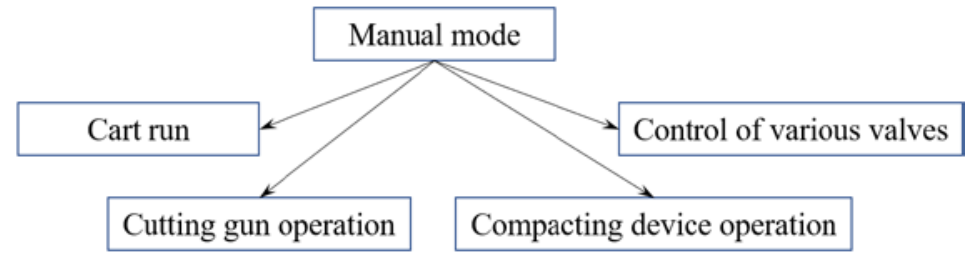

Fig. 3 Manual control mode

In the automatic state, after the system power on, press the cutting start, the system began to work, and its software flow as shown below.

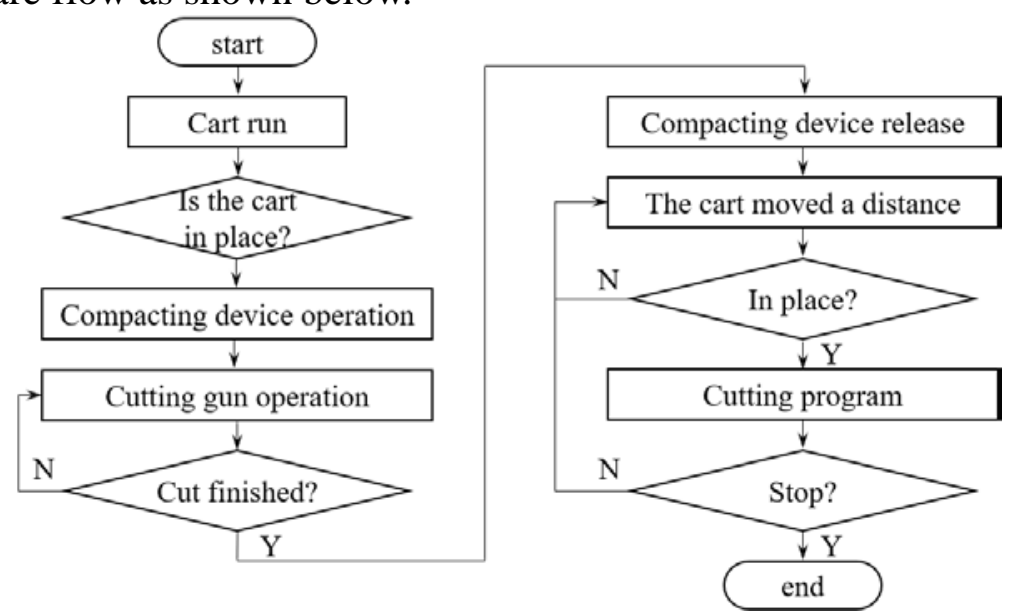

Fig. 4 Automatic control mode 


\section{Conclusion}

Based on the detailed analysis of the existing plate cutting processing machine working principle, the design of PLC based control system, but the system to meet the high efficiency, high reliability, high automation and other requirements.

\section{Acknowledgment}

The research is funded by the research project of education and teaching reform in Beihua University (Research and practice of curriculum reform of material engineering specialty based on OBE-CDIO).

\section{Reference}

[1] Sun Chengzhi. Teaching and Phyback in Two Axis Motion Control Based on PLC[J]. Modular Machine Tool \& Automatic Manufacturing Technique,2010(3):65-67.

[2] Wu Qian. The research of key technology of high-speed glass fiber \& magnesium cement board [D]. Jiangsu University of Science and Technology, 2014.

[3] Tian Lixin. Design and implementation of motion control system for plate cutting machine based on PLC[J]. Hydro-mechatronics Engineering,2015,43(24).

[4] Liu Guangrui. Design of PLC control system for plane cutter[J].Mining \&Processing Equipment, 2011(7): 131-134.

[5] Gao Zhi. The design of hot wire cutting machine control system based on PLC and LABVIEW [J]. Manufacturing Automation,2013(19):143-146. 